\title{
Correction to: Freshwater fish functional and taxonomic diversity above and below Niagara Falls
}

\author{
Karl A. Lamothe · Justin A. G. Hubbard • \\ D. Andrew R. Drake
}

\section{Correction to: Environmental Biology of Fishes https://doi.org/10.1007/s10641-020-01044-w}

The original version of this article unfortunately contained mistakes.

The corrections are given in the following list:

(1) The copyright holder name should be changed from "C) The Author(s) 2020" to "(C) Her Majesty the Queen in Right of Canada 2020".

(2) In Discussion section, 4th paragraph, 5th sentence, the word 'juvenile' should be removed before 'Atlantic Salmon'. The sentence should be rewritten as: "Nevertheless, a unique catch that occurred in October of 2015 at one of the most northern sites in the lower Niagara River was a single Atlantic Salmon".

The original article can be found online at https://doi.org/ 10.1007/s10641-020-01044-w.

K. A. Lamothe $(\bowtie) \cdot$ J. A. G. Hubbard · D. A. R. Drake Great Lakes Laboratory for Fisheries and Aquatic

Sciences, Fisheries and Oceans Canada, Burlington, Ontario, Canada

e-mail: karl.lamothe@dfo-mpo.gc.ca

Present Address:

J. A. G. Hubbard

Department of Physical \& Environmental Sciences, University of Toronto Scarborough, Scarborough, Ontario, Canada
(3) The author mistakenly did not report the full field team involved in sampling in the acknowledgements, and thus would prefer simply to list "the many individuals involved in field sampling", and remove the ", including Robin Gáspárdy, Jason Barnucz, Calder Robinson, Meg Sheldon, Kurtis Smith, Sara Smith, Noel Soogrim, Erik Tuononen, Alex Verkuyl, Nicholas Wasilik, Carly White, Mallory Wiebe, and Kirsten Wuerch".

The original article has been corrected.

Publisher's Note Springer Nature remains neutral with regard to jurisdictional claims in published maps and institutional affiliations. 